\title{
Spatial distribution of developmental egg ages within a herring Clupea harengus spawning ground
}

\author{
Yorgos Stratoudakis $^{1, *}$, Alejandro Gallego ${ }^{1,2}$, John A. Morrison ${ }^{1}$ \\ ${ }^{1}$ FRS Marine Laboratory, Victoria Road, Aberdeen AB11 9DB, Scotland, UK \\ ${ }^{2}$ Zoology Department, University of Aberdeen, Tillydrone Avenue, Aberdeen AB24 2TZ, Scotland, UK
}

\begin{abstract}
Herring Clupea harengus are demersal spawners that lay their eggs in continuous, multilayer mats on coarse sediment. Although the reproductive biology of herring is extensively studied, little is known about the processes of egg deposition and development within a spawning ground. Here, the spatial distribution of developmental egg ages from a spawning ground (Ballantrae Bank, west of Scotland) is modelled using regression trees and generalised additive models. We refer to developmental, rather than absolute, ages to indicate that ageing the eggs according to the apparent state of development in the samples may underestimate their true age. Egg development was found to be related to the position within the egg mat (horizontal and vertical), the sampling day and the egg density in the samples. Eggs near hatching ( 12 to $14 \mathrm{~d}$ old) were mainly deposited at the eastern and northeastern bounds of the mat, where eggs in the top layer exceeded the developmental age of eggs in the bottom layer. Newly laid eggs ( 1 to $2 \mathrm{~d}$ old) were found in the western parts of the ground, where substrate type was less suitable and egg densities were lowest. The results suggest that spawning progressed in a westerly direction over a period of at least $2 \mathrm{wk}$, constrained by the availability of suitably coarse sediment. The presence of eggs in the bottom layer with lower developmental age than in the top demonstrates that multiple layering causes developmental retardation nearest to the substrate. Developmental retardation can therefore be seen as a contributing factor in the reported variability in hatching lengths of herring larvae.
\end{abstract}

KEY WORDS: Atlantic herring · Egg deposition - Development - Spatial distribution

\section{INTRODUCTION}

Herring Clupea harengus are unique among clupeoids and rare among teleost fish in having a demersal egg phase. During spawning, shoals of mature herring congregate near the seabed, where females perform specialised movements to deposit their eggs on the substrate, and males 'spray' the surrounding area with milt (Haegele \& Schweigert 1985). Herring eggs have a slightly negative buoyancy and quickly stick to the sediment and to each other, gradually building a fairly uniform multi-layer mat ( 5 to 10 layers thick) along the spawning ground (Napier 1993). Sev-

\footnotetext{
- Present address: Instituto de Investigaçāo das Pescas e do Mar (IPIMAR), Avenida de Brasilia 1400, Lisboa, Portugal E-mail:yargos@ipimar.pt
}

eral hypotheses have been suggested to explain the mechanisms that may lead to the deposition of a relatively uniform egg mat (Haegele \& Schweigert 1985, Hay 1985, 1990, Sherwood et al, 1991), although these have rarely been tested against observations from spawning grounds in nature. Here, eggs sampled at Ballantrae Bank, one of the few well-studied Atlantic herring spawning grounds (Baxter 1971, Morrison et al. 1991. Napier 1993), are used to map the spatial distribution of developmental egg ages (see 'Materials and methods' for a definition) within the ground. This allows one to reconstruct the spatial patterns of egg deposition in Ballantrae Bank, and therefore to infer empirically the movements of the spawning adults. The data analysis is based on regression trees (Breiman et al. 1984) and generalised additive models (Hastie \& Tibshirani 1990), 2 recent statistical 
tools particularly suitable for summarising complex data sets (e.g. Smith et al. 1997) and discovering functional relationships between variables of interest (e.g. Chalupka \& Limpus 1997, Stratoudakis et al. 1998), with no need for strong assumptions with regard to the distribution of the data.

\section{MATERIALS AND METHODS}

Herring eggs were collected at Ballantrae Bank $\left(55^{\circ} \mathrm{N}, 5^{\circ} \mathrm{W}\right)$ during a cruise of the RV 'Clupea' in the Clyde Sea (west of Scotland) on 10 to 18 April 1993 (Stratoudakis 1993). The main aim of the survey was to assess the spawning biomass of the spring-spawning Clyde herring using the fisheries-independent egg production method (Gunderson 1993). Samples were collected from the seabed with a Day grab (bite area $0.1 \mathrm{~m}^{2}$ ). A $32 \mathrm{~mm}$ diameter cylindrical core was used to collect 1 quantitative sample from each station where eggs were recovered by the grab (57 out of 350, Fig. 1). Latitude and longitude were recorded at all stations using the Decca navigation system and the prevailing substrate type in each grab sample was visually inspected and characterised (stones, gravel, sand or mud). The spawning ground was located on 11 April, and eggs were also recovered from stations sampled on 13 and 14 April. Sampling took place during the final stages of spawning. In the last days of the survey, any trace of spawning fish in and around the bank had disappeared.

The core samples (eggs attached to substrate) were preserved in $5 \%$ formaldehyde solution. In the laboratory, 100 eggs were manually separated from the top and the bottom of the core, identifying the vertical orientation of the sample from the presence of sediment particles. The remaining eggs from each core were separated using a $5 \%$ sodium hydroxide solution and counted under a binocular microscope at low magnification. The 100 eggs selected from the top and the bottom of each core (loosely termed the top and bottom layer respectively) were used to describe the development of eggs according to a scale of 6 stages (Table 1). This scale was based on previous studies of herring
Table 1 Clupea harengus. Correspondence between herring egg developmental stage and egg age (d) from fertilisation. This relationship (Gallego 1989) was derived from eggs incubated in the laboratory, in a single layer and at the sea water temperature measured on the bank at the time of the survey $\left(7^{\circ} \mathrm{C}\right)$. Values in brackets are those used for translating stage to developmental age (mid-point of the age range attributed to each stage)

\begin{tabular}{|llr|}
\hline Stage & Description & Equivalent age \\
\hline 1 & $\begin{array}{l}\text { From fertilisaton to } \\
\text { pluri-cellular morula }\end{array}$ & $0-1(0.5)$ \\
3 & $\begin{array}{l}\text { From blastula to the } \\
\text { completion of gastrulation } \\
\text { Lips of the blastopore closed. }\end{array}$ & $1-4(2.5)$ \\
& $\begin{array}{l}\text { Head mesoderm not differ- } \\
\text { entiated from trunk mesoderm. }\end{array}$ & \\
& $\begin{array}{l}\text { Eyes not visible } \\
\text { Keel of anterior portion of head } \\
\text { risen out of yolk. Tail grown free } \\
\text { but not reaching head. }\end{array}$ & $8-10(9.0)$ \\
& $\begin{array}{l}\text { Eyes visible } \\
\text { Posterior part of tail coiling } \\
\text { past level of head. Eyes } \\
\text { well-formed but not pigmented } \\
\text { Tail extending well past the level } \\
\text { of head. Eyes pigmented }\end{array}$ & $10-13(11.5)$ \\
6 & $\begin{array}{l}13-15(14.0) \\
6\end{array}$ & \\
\hline
\end{tabular}

egg development (Volodin 1960, Baxter 1971), covering the development of herring embryos from fertilisation to just prior to hatching.

Egg stages were a posterioni transformed to ages based on the results (Gallego 1989) of an experiment where Ballantrae Bank herring eggs were incubated under controlled laboratory conditions from fertilisation to hatching, 15 to $16 \mathrm{~d}$ later. The temperature during the laboratory experiment was $7^{\circ} \mathrm{C}$, equivalent to the average sea bottom temperature at Ballantrae Bank in April (Napier 1993). The development of the eggs was carefully monitored daily, which allowed us to associate each of the 6 stages described in Table 1 with a range of days from fertilisation. The translation of stage to age was dependent on the analyst's interpretation, but this should not be any more subjective than any other staging analysis. Individual egg stages were consequently transformed to ages, represented

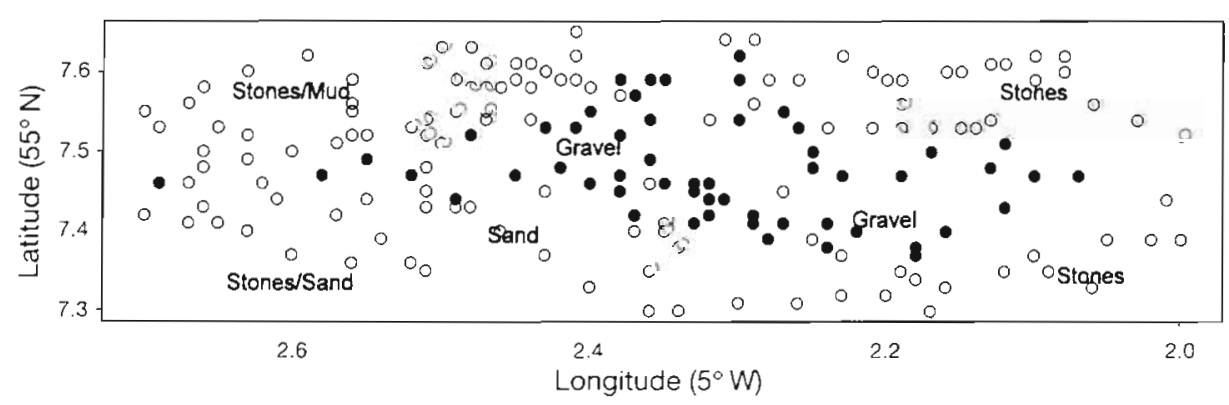

Fig. 1. Sampling locations within the survey area at Ballantrae Bank (Clyde Sea, West of Scotland) during April 1993. (O) Stations without eggs, (•) stations where eggs were found. The broad types of prevailing sediment over the study area are displayed on the plot 
by the mid-point of the age interval associated with each stage (Table 1). The mean age from all eggs in 1 layer provided a univariate summary of egg age for a given layer and station for statistical modelling. In the experiment, eggs were incubated in a single layer, whereas in the multi-layer mats observed in nature the development of eggs in the deeper layers can be delayed ('developmental retardation', Alderdice \& Hourston 1985). The developmental rate of the eggs in this reference collection will therefore be maximal for that temperature, due to the absence of developmental retardation. Therefore, we refer to 'developmental age' of herring eggs throughout the text, because the age ascribed to these eggs would only be equivalent to their 'true' age in the absence of developmental retardation.

In the first step of the analysis, a regression tree (Breiman et al. 1984) was used to explore relationships between developmental egg ages and the explanatory variables of interest:

Age - Latitude + Longitude + Total + Layer + Day

where 'latitude' and 'longitude' (in decimal minutes) describe the co-ordinates of the sample location, 'total' is the number of eggs in the core sample, 'layer' is a categorical variable indicating whether the eggs came from the top or bottom layer of the mat and 'day' is the sampling day. Model building followed the standard cut-off criteria used in S-PLUS (change in deviance $<1 \%$ of the root node deviance or $<10$ observations in a node). These cut-off criteria usually result in model overfitting, and, to obtain a more parsimonious model, cross-validation and subsequent pruning were performed (Venables \& Ripley 1994). Although there are no formal tests for comparing the significance of the differences between competing tree-based models, cross-validation and pruning for the optimal number of nodes provides the tree with the smallest prediction error.

Based on the results of the regression tree, generalised additive models (GAMs) were fitted separately to the developmental egg ages from the top and bottom layer. GAMs form a powerful modelling tool by allowing arbitrary smooth functions (smoothers) to determine the best fit to the data (Hastie \& Tibshirani 1990). The fitted effect of the explanatory variables is additive, so several variables and variable degrees of smoothing are allowed in the same model.

The model initially selected was:

Age

LOESS (Latitude, Longitude) + Day + LOESS (Total)

where latitude and longitude are fitted as a LOESS (Cleveland 1981) smooth surface to account for the potential spatial interaction in developmental age re- vealed by the regression tree (see 'Results'), sampling day is fitted as a linear effect and total eggs are fitted as a LOESS smooth curve. The significance of each term in the fitted model was tested using approximate F-tests and terms were reduced when non-significant at the $5 \%$ level. Inspection of residual plots indicated that the selection of normal errors was adequate.

\section{RESULTS}

The herring spawning ground in Ballantrae Bank during April 1993 was estimated to cover an area of approximately $160000 \mathrm{~m}^{2}$ (Stratoudakis 1993). Eggs were almost exclusively found on gravel, although small concentrations at the edges of the mat were recovered on sand or stones (Fig. 1). The total number of eggs in the core samples ranged between 600 and 2000 eggs, equivalent to $750000-2500000$ eggs $\mathrm{m}^{-2}$. The apparent developmental ages in the samples ranged from eggs newly laid ( $1 \mathrm{~d}$ old) to eggs close to hatching (12 to $14 \mathrm{~d}$ ). In general, eggs in the bottom layer were more developed and had a smaller range of development across stations than eggs in the top layer, although the maximum developmental age in the top layer was slightly higher than in the bottom (Fig. 2).

Fig. 3 shows the selected regression tree after crossvalidation and pruning. The first separation is between samples with egg densities above and below 1100 eggs per core. For low egg densities, there was no evidence of differences in developmental age between the top and bottom layer, the only noticeable split being due to the date of sampling. For egg densities higher than 1100 eggs per core, the most important split was between eggs in the top and bottom layers. For eggs in the top layer, there was a clear spatial separation, with older eggs on the eastern parts of the ground and an

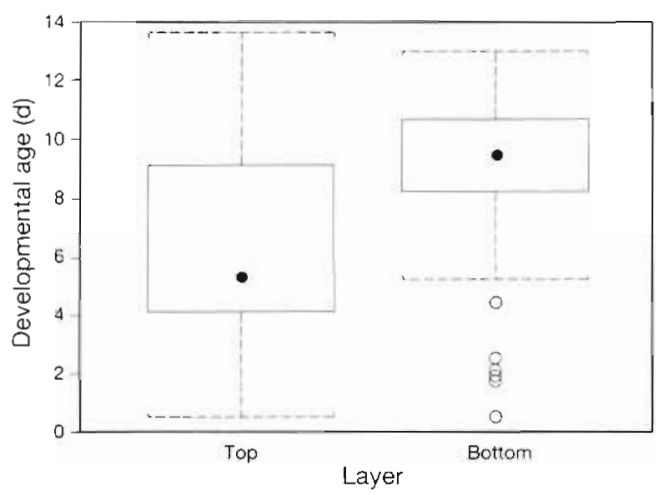

Fig. 2. Clupea harengus. Boxplot of developmental egg age in the top and bottom layers of the herring spawning ground at Ballantrae Bank during April 1993. ( Median; box edges depict the inter-quartile range and whiskers 1.5 times the inter-quartile range. (0) Outliers 


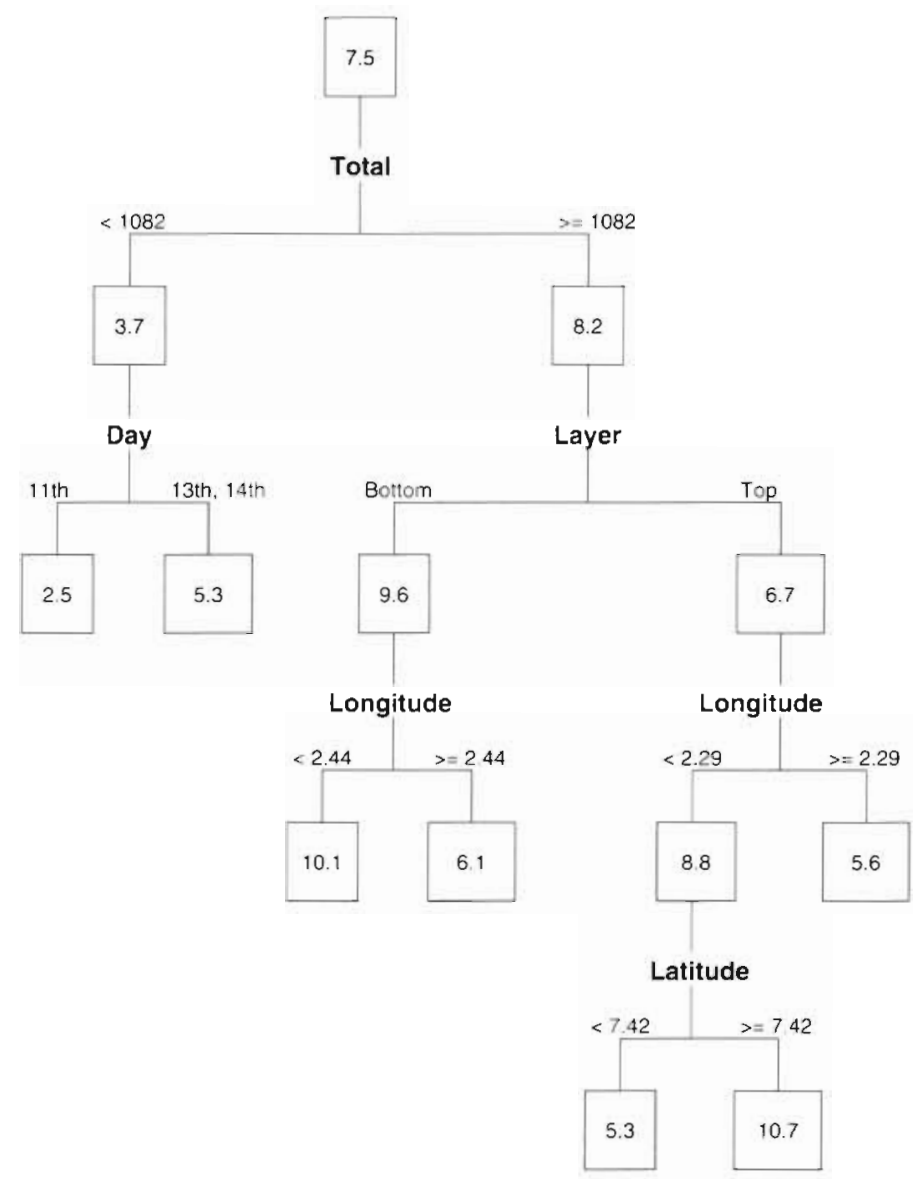

Fig. 3. Clupea harengus. Regression tree fitted to developmental age of herring eggs sampled in the Ballantrae Bank spawning ground during spring 1993. Values in boxes are fitted developmental ages at each level of the tree partition. Variables in boldface are those significant for the ensuing binary partition. The levels of the explanatory variable that lead to different branches of the tree are indicated at each splitting point. For example, the first partition of the tree is due to egg density. Mean developmental age in stations with < 1082 eggs per core is $3.7 \mathrm{~d}$, whereas in stations with $\geq 1.082$ eggs the mean age is $8.2 \mathrm{~d}$

additional latitudinal effect within that area. A similar, although simpler, spatial pattern was evident for the eggs in the bottom layer, with older eggs in the eastern edge of the ground. Although the average developmental age in the top layer was $3 \mathrm{~d}$ less than in the bottom, the oldest fitted ages occurred in the top layer at the easterly edge of deposition (average $10.7 \mathrm{~d}$ ).

Fig. 4 summarises the results for the GAM fitted to developmental egg ages in the top layer of the egg mat. Each panel depicts the partial effect of each explanatory variable on egg ages after removal of the effects of other significant variables. For the spatial variables (latitude and longitude) the partial effect is a smooth surface, since the 2 variables have a significant interaction $(F=30.3, \mathrm{p}<0.001)$. Developmental age was highest in the east and northeast edges of the ground and gradually decreased in a southwesterly direction. Although this interaction is not significant in the model for the bottom layer $(F=2.35, \mathrm{p}=0.137)$, a similar spatial pattern is observed (Fig. 5), whereby developmental egg age linearly decreases with longitude $(F=22.1, \mathrm{p}<0.001)$ and increases with latitude $(F=18.3, p<0.001)$. In both models, the total number of eggs in the core is significant as a smooth curve $(F=$
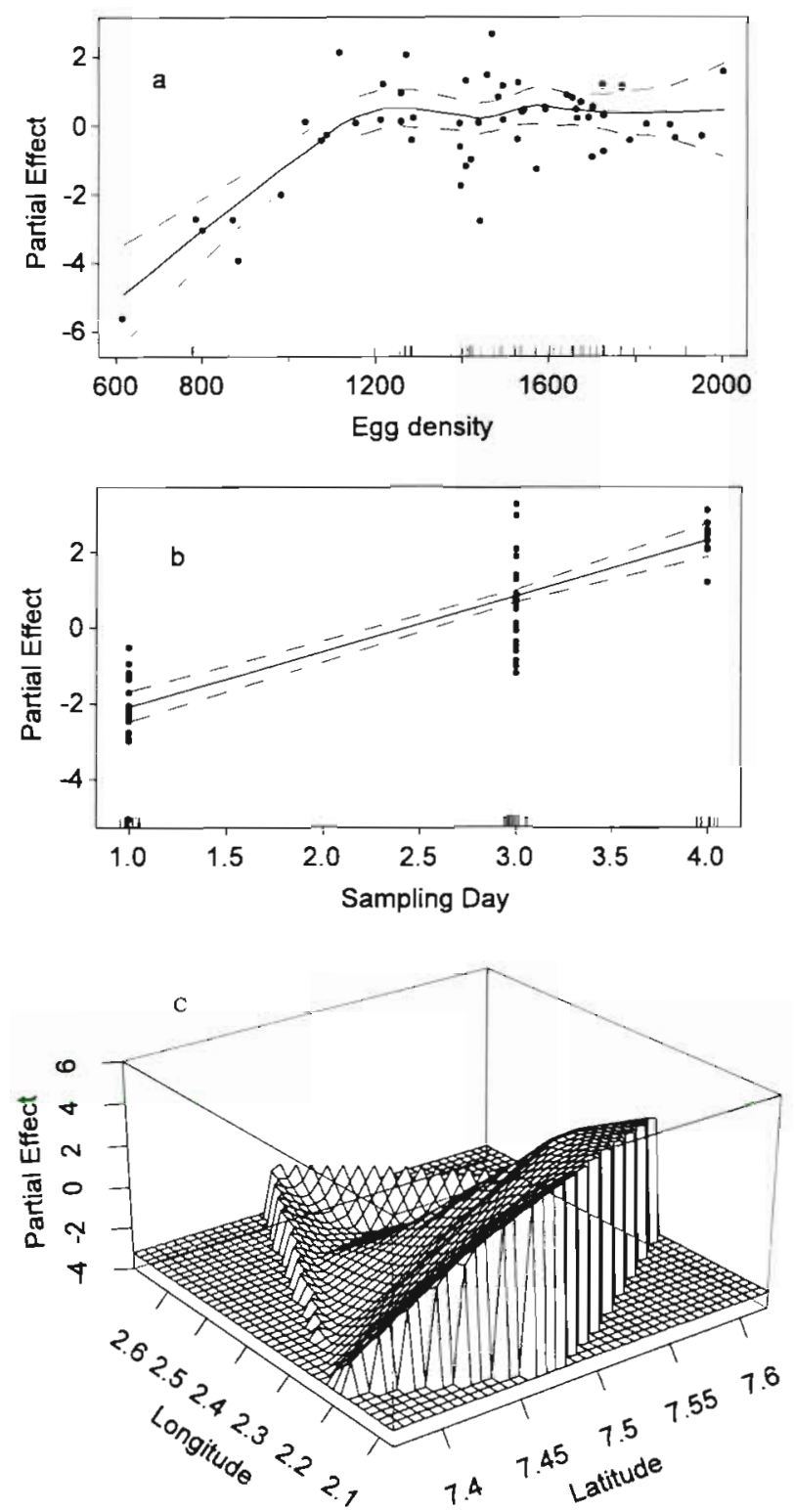

Fig. 4. Clupea harengus. Effect of (a) egg density, (b) sampling day, and (c) spatial variables on developmental egg age in the top layer of the herring spawn in Ballantrae Bank (April 1993). (a, b) Univariate partial effects (scarterplot smooths); (c) combined effect of latitude and longitude (bivariate LOESS smooth) due to the presence of a significant spatial interaction 

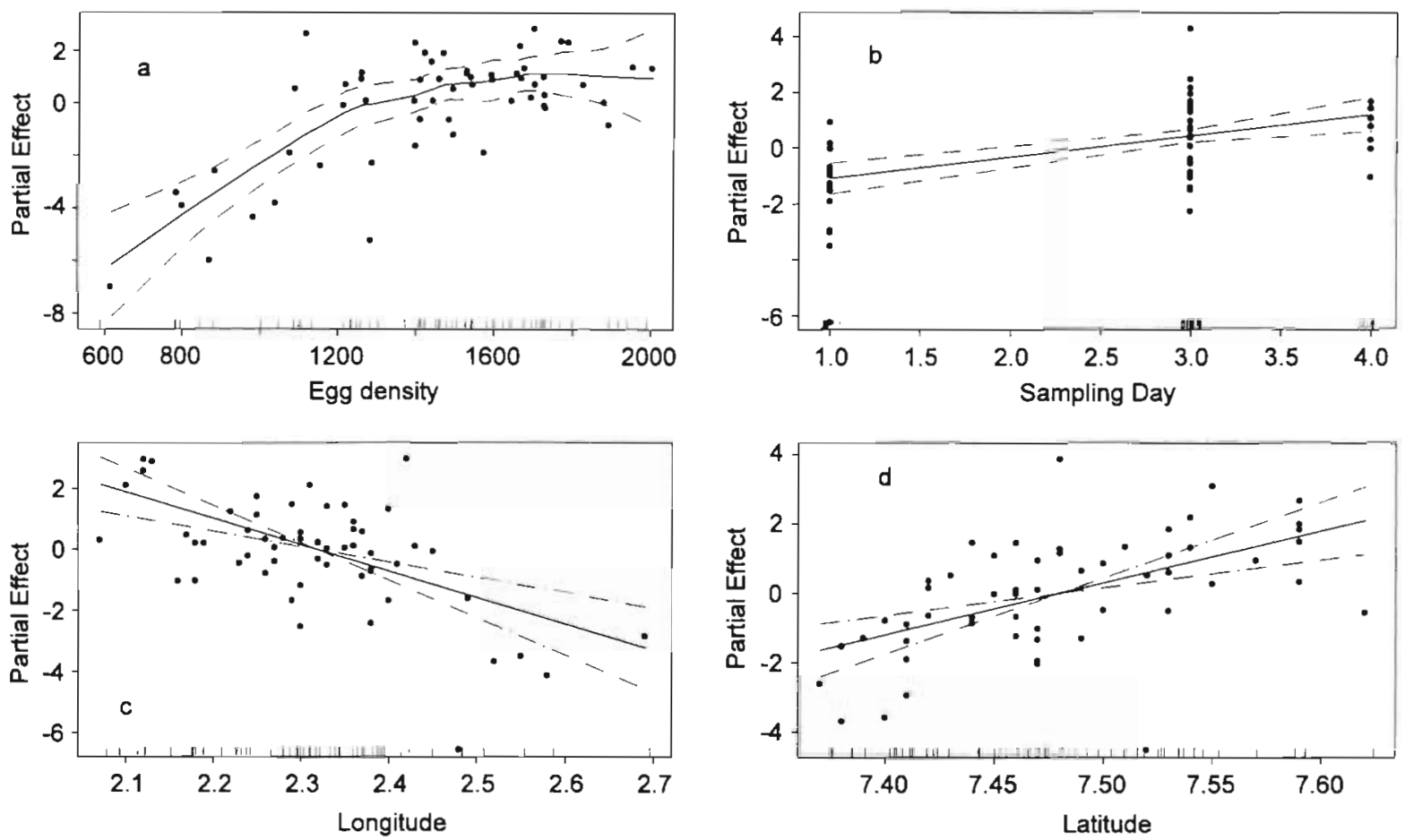

Fig. 5. Clupea harengus. Effect of (a) egg density, (b) sampling day, (c) longitude, and (d) latitude on developmental egg age in the bottom layer of the herring spawn in Ballantrae Bank (April 1993). All panels depict univariate partial effects (scatterplot smooths)

6.99, $\mathrm{p}<0.001$ and $F=3.88, \mathrm{p}=0.013$ for the top and bottom layers respectively), with a linear increase for low egg densities and no trend for densities higher than 1100 to 1200 eggs per core. Similarly, in both models, there is a highly significant effect of sampling day $(F=81.44, \mathrm{p}<0.001$ and $F=12.94, \mathrm{p}<0.001$ for the top and bottom layers respectively), with the rate of increase per day being higher in the top layer. These results are consistent with the broad patterns revealed by the regression tree (Fig. 3).

\section{DISCUSSION}

The significant spatial effects observed in the models fitted to developmental egg ages spawned in Ballantrae Bank in spring 1993 suggest directionality in spawning by the herring. This directionality can be illustrated by interpolating the predicted values from the 2 models and plotting surfaces of developmental ages along the egg mat (Fig. 6). The surface plots show a similar general pattern in the spatial distribution of egg ages in the 2 layers, suggesting that spawning progressed from the east and northeast edges of the ground in a westerly direction, while being constrained by the availability of suitably coarse sediment. Egg deposition was fairly uniform along the ground apart from the low egg densities (<1100 eggs per core) shown to be associated with the final stages of spawning. Some of the remaining variation in egg density could be attributed to the preference of herring to spawn along the peaks of the gravel ripples (Gallego 1989) that characterise the spawning ground in Ballantrae Bank.

The observed dissimilarities between the spatial effect in the 2 models could be due to slightly different spatial patterns of egg deposition over time. However, the different slopes in the relationship between developmental egg age and sampling time in the 2 layers, together with the presence of eggs with a higher apparent age in the top layer, suggest that developmental retardation might also contribute towards the modelled spatial differences between the 2 layers. Developmental retardation in multi-layered herring spawn has been described in the literature (Baxter 1971, Alderdice \& Hourston 1985), and is believed to act through the restriction of water circulation in the deeper layers of the egg mat. This reduces oxygen availability and flushing of metabolic waste products (Napier 1993). In some cases, multi-layering has been linked with high egg mortality near the substrate (Alderdice \& Hourston 1985), although this was not observed in the present study.

The ultimate effect of retardation is to reverse the vertical pattern of development within the egg mat, thereby allowing eggs in the top layers to hatch earlier. 

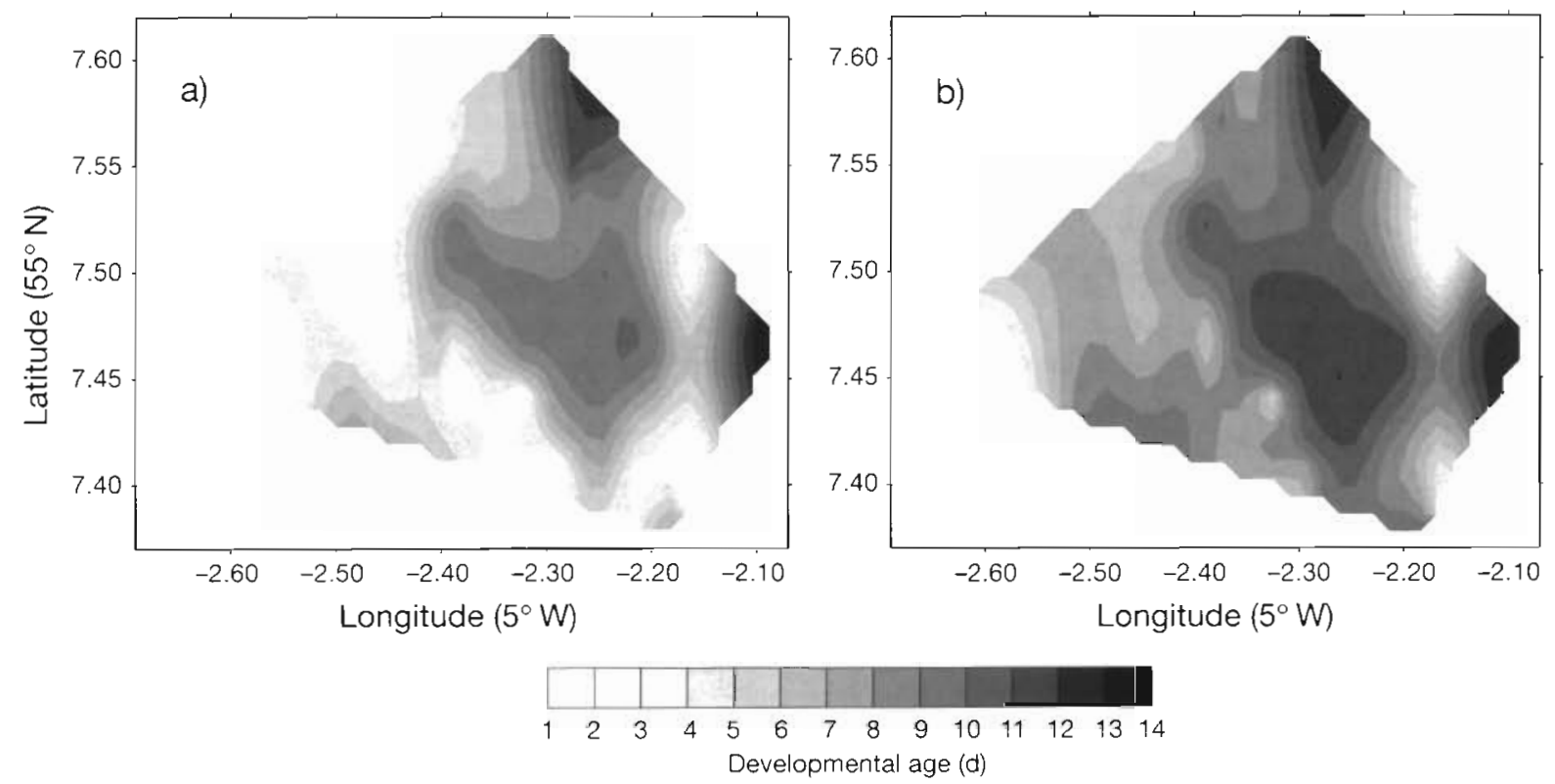

Fig. 6. Clupea harengus. Shaded contour plot of fitted developmental egg ages in (a) the top and (b) the bottom layers of the herring spawning ground of Ballantrae Bank (Aprjl 1993)

However, hatching takes place with the release of enzymes that break down the egg membrane (Blaxter 1969). The release of these enzymes will influence the micro-environment of adjacent layers and might trigger the breakdown of membranes of neighbouring eggs. It is therefore possible that embryos in the vicinity of hatching eggs will be forced to hatch prematurely. Thus, retardation in the bottom layers of multi-layer egg mats can be seen as one of potential causes of the large variation in length at hatching observed in herring larvae (Rankine et al. 1990)

\section{LITERATURE CITED}

Alderdice DF, Hourston AS (1985) Factors influencing development and survival of Pacific herring (Clupea harengus pallasi) eggs and larvae to beginning of exogenous feeding. Can J Fish Aquat Sci 42(Suppl 1):56-68

Baxter IG (1971) Development rates and mortalities in Clyde herring eqgs. J Cons Int Explor Mer 160:27-29

Blaxter JHS (1969) Development: eggs and larvae. In: Hoar WS, Randall DJ (eds) Fish physiology, Vol III. Academic Press, London, p 177-252

Breiman L, Friedman JH, Olshen RA, Stone C.J (1984) Classification and regression trees. Wadsworth, Belmont ( $A$

Chalupka MY, Limpus CJ (1997) Robust statistical modelling of hawksbill sea turtle growth rates (southern Great Barrier Reef). Mar Ecol Prog Ser 146:1-8

Cleveland WS (1981) LOESS: a program for smoothing scatterplots by robust locally weighted regression. Am Stat 35:54

Gallego A (1989) Distribution, abundance and survival of herring eggs in a natural spawning ground. MSc thesis, University of Wales, Bangor

Gunderson DR (1993) Surveys of fisheries resources. Wiley, New York
Haegele CW, Schweigert JF (1985) Distribution and characteristics of herring spawning grounds and description of spawning behaviour. Can J Fish Aquat Sci 42(Suppl 1):39-55

Hastie T, Tibshirani R (1990) Generalised additive models. Chapman \& Hall, London

Hay DE (1985) Reproductive biology of Pacific herring (Clupea harengus pallasi). Can J Fish Aquat Sci 42 (Suppl 1): $111-126$

Hay DE (1990) Tidal influence on spawning time of Pacific herring (Clupea harengus pallasi). Can J Fish Aquat Sci 47:2390-2401

Morrison JA, Napier IR, Gamble JC (1991) Mass mortality of spring spawning herring eggs associated with a sedimenting diatom bloom. ICES J Mar Sci 48:237-245

Napier IR (1993) The organic carbon content of gravel bed herring spawning grounds and the impact of herring spawn deposition. J Mar Biol Assoc UK 73:863-870

Rankine PW, Cargill LH, Morrison JA (1990) Varlation in the hatching length of spring-spawning herring larvae (Clupea harengus L.) on Ballantrae Bank in the Firth of Clyde. J Cons Int Explor Mer 46:333-339

Sherwood $\mathrm{N}$, Kyle A, Kreiberg $\mathrm{H}_{1}$ Warby CM. Magnus $\mathrm{TH}_{1}$ Carolsfeld J, Price WS (1991) Partial characterisation of a spawning pheromone in the herring Clupea harengus pallasi. Can J Zool 69:91-103

Smith SJ, Iversen SJ, Bowen WD (1997) Fatty acid signatures and classification trees: new tools for investigating the foraging ecology of seals. Can J Fish Aquat Sci 54:1377-1386

Stratoudakis $Y$ (1993) A study of herring egg distribution, mortality and development at Ballantrae Bank in 1993. MSc thesis, University of Wales, Bangor

Stratoudakis Y, Fryer RJ, Cook RM (1998) Discarding practices for commercial gadoids in the North Sea. Can J Fish Aquat Sci 55(7):1632-1644

Venables WN, Ripley BD (1994) Modern applied statistics with S-plus. Springer-Verlag, New York

Volodin VM (1960) Embryonic development of the autumn Baltic herring and their oxvgen requirements during the course of development. Fish Res Bd Can Trans Ser 252 